\title{
Reviews on Issuing History of China's Sports Lotteries and Research in Legislation Countermeasures
}

\author{
Li Chunlin \\ Ji'nan Unviersity, Sports Department, Guangzhou 510632
}

\begin{abstract}
Keywords: sports lotteries; current issuing situations; current problems; legislation suggestions; countermeasures.
\end{abstract}

\begin{abstract}
Starting relatively late, China's sports lottery industry suffers from an immature market. In order to learn the issuing situations, management methods and existing problems of China's sports lotteries in recent decade, by means of documents and materials and inspections, this thesis researches the issued amount, types, characteristics and current management patterns of China's sports lotteries over the years and analyzes the development tendency of international sports lotteries and development prospects of China's sports lotteries. Then several glimpses are thrown to the relevant problems in China's lottery legislation and finally some countermeasures are proposed to guarantee a healthy development of China's lottery industry.
\end{abstract}

\section{Introduction}

China' sports lottery has been issued since 1994 when the sales amount reached 500 million yuan, with only type "instant games" available; in 2002, the sales amount of China's sports lotteries proved to be 21.7 billion yuan, in which that of computer lottery reached 14 billion yuan, that of football lottery 6 billion yuan and that of instant games 1.7 billion yuan. Therefore compared with those in 1994, sales types and amount of lottery in 2002 enjoyed huge development. During the past nine years, the aggregate sales amount of China's sports lotteries has amounted to 55.939 billion yuan and 17.878 billion public welfare funds have been created. The distribution proportion of public welfare funds according to different purpose reveals that 60 percents have been invested in Nationwide Body-building Plan and 40 percents in Olympic Glory Plan which propels and contributes to the reform and development of China's sports[1]. In order to learn the development history and laws of China's sports lotteries in the past decade, this thesis conducts researches in the issuing and marketing of sports lotteries and the distribution, management and purpose of public welfare funds in hope of providing references for future healthy development of sports lottery.

\section{Basic Situations of China's Sports Lottery}

In order to accelerate the development of sports, make up the shortage in sports and collect funds for Nationwide Body-building Plan and Olympic Glory Plan, with the approval of the State Council, sports lottery began to be issued in 1994 in China. In China, sports lottery can not be registered, reported for loss and circulated and its principle can not be returned. Sports lottery in China turns out to be issued based on the principles of transparence, justice and fairness; should be issued, printed and sold in uniform; certain quotas, regions and procedures should be predetermined and violations of disciplines and regulations are forbidden legally, audited strictly and punished severely. Winning methods should be launched when the sports lotteries are sold and lotteries should be drawn in public under the supervision of notaries. Drawing results should be released immediately at points of sales. Winners should receive their respective lottery prizes with valid lotteries according to formulated procedures. Prize money of traditional lotteries sold on internet should be paid in RMB cashes. Public welfare funds of China's sports lottery should be administered by the special fund set up by financial departments of sports lottery administrative organizations at all levels and should be specially utilized to develop sports. Relevant institutions are required to release its utilization purpose regularly to the society to receive public supervisions. None department, unit and person is allowed to intercept or appropriate the public welfare funds for any reason[2]. Issuing, 
marketing and relevant economic activities of China's sports lottery must be conducted under the audit supervision from the audit department of the government at the same level.

\section{Current Issuing Situations of China's Sports Lottery}

\section{Issuing quotas of sports lottery over the years.}

Known as "the sixth largest industry", essentially speaking, even though lottery industry can not create values, as an approach to redistribute social resources, it attracts universal attentions thanks to its powerful ability to collect idle capitals in society. With currently more than 100 countries all over the world issuing all kinds of lotteries, lottery industry has become an important channel to collect social public welfare funds for governments at all levels. Enjoying increasing popularity, lottery has taken a path of high-speed development in some middle and large cities. In the meantime, as a common good which can be purchased anytime, computer lotteries emerge at large streets and small lanes. During the last dozens of years, under the direct leadership of State General Administration of Sports and supports and attentions from sports committees at all levels, with the meticulous organization and joint efforts of the sports lottery managers across the whole country, sports lottery industry has fulfilled remarkable achievements, from the launch of sports lottery to national operation, from team establishment to national connected computer lottery sales then to tolerable market size[3]. Lottery circulation increases with each passing year, the sales amount and public welfare funds of sports lottery are listed as follows over the nine years:

Sales Amount and Contributed Public Welfare Funds of Sports Lottery from 2002 to 2010 Unit: 100 million yuan

\begin{tabular}{ccccccccccc}
\hline Time & $\begin{array}{c}200 \\
2\end{array}$ & 2003 & 2004 & 2005 & 2006 & 2007 & 2008 & 2009 & 2010 & Aggregate \\
\hline $\begin{array}{c}\text { Sales } \\
\text { amount }\end{array}$ & 5 & 5 & 12 & 15 & 24.99 & 39.99 & 90.72 & 149.3 & 217 & 559.3 \\
$\begin{array}{c}\text { Public } \\
\begin{array}{l}\text { Welfare } \\
\text { funds }\end{array}\end{array}$ & 1.5 & 1.5 & 3.6 & 4.0539 & 7.5951 & 12.1113 & 27.4592 & 44.79 & 75.95 & 178.78 \\
$\quad$ & & & & & & & & & & \\
Growth rate & - & 0 & 0.46 & 0.25 & 0.67 & 0.60 & 1.26 & 0.65 & 0.56 & - \\
\hline
\end{tabular}

(Above Statistics Stem from the Sports Lottery Announcements of the Past Year Released by People's Daily and China Sports Daily from 2002 to 2010)

\section{Current types of issued lottery.}

Lottery is a paper printed with numbers and figures (characters) and bought by people voluntarily, with which buyers can prove their ownership and obtain prizes according to regulated rules. With the approval of the State Council, two kinds of lotteries are in circulation currently: sports lottery and welfare lottery, which are held by State General Administration of Sports and Ministry of Civil Affairs respectively[4]. According to how the numbers are drawn and playing methods, lotteries can be classified into traditional ones, instant ones, lotto ones, quiz ones and computer traditional ones.

Issuing characteristics of lottery.

Taking lottery industry as an important channel to collect public welfare funds, governments at all levels are responsible to support lottery industry and provide it with legal protections and public supervisions and inspections. A series of preferential policies for lottery issuing implemented by central government enables lottery industry to take a universally recognized and legal position. 


\section{Current Problems in Issuing Sports Lottery}

Remarkable achievements as China's sports lottery has fulfilled, we are supposed to realize that due to a short development history in China, compared with developed countries, the issuing approaches and sales amount suffer from huge gaps. In the meantime, some problems that have emerged during its development are as follows:

Immature management system and operation mechanism.

The current management system of China's lottery industry is that with the approval of the State Council, Ministry of Civil Affairs and State General Administration of Sports are responsible to issue welfare lottery and sports lottery respectively. Before July, 1999 it was People's Bank of China who was responsible to take charge of issuing lotteries after which Ministry of Civil Affairs turned out to be responsible to issue lotteries. Currently with no uniform lottery management regulations formulated by central government and no lottery management system determined, institution functions and formation fail to satisfy the development demands of lottery industry. Therefore if no reforms are implemented, a sustainable development of sports lottery will not be guaranteed[5].

Shortage of relevant policies and regulations.

When it comes to lottery, its legislations prove to be predetermined before issuing in many countries. By means of legislation, governments at all levels provide lottery industry with preferential policies and protecting measures and guarantee legal operation and management, by which healthy development within the legal system of lottery industry can be ensured; nonetheless, during the past ten years, no special laws have been implemented. Currently it is the administrative regulations issued by the State Council as well as its competent departments that the lottery industry depends on. With the current regulations (including documents, notices and local regulations) too abstract and general, no detailed penalty provision is available, making the existing regulations performing no practical functions.

Weak market supervision on lottery industry results into numerous improper factors.

Amazing development potentials as China's sports lottery market presents, numerous unreasonable factors have emerged due to weak supervision. For instance some regions and departments alter the issuing approaches and playing rules of lottery without approval and launch misleading information to the public in their promotions; illegal actions exist in some regions, including to sell "Mark Six" on a commission basis and issue private lottery tickets; the issuing management provision and capital and financial management system of lottery are full of defects; the range of application of lottery public welfare funds proves to be over-narrow. All these factors impose huge influences on the normal development of lottery industry.

\section{Pondering Over Legal Management in the Future Development of China's Lottery Industry}

\section{To establish China Lottery Regulatory Commission.}

It is an integral measure to enhance supervision and management of lottery market in order to promote the beneficial and abolish the harmful of lottery industry. Therefore it is suggested that government establish the special supervision organization "China Lottery Regulatory Commission" which is similar with "China Securities Regulatory Commission" and detached from department interests and formulate a series of authoritative supervision rules in order for a specialized, institutionalized and routinized supervision on lottery market. Since it is beyond doubt that lottery industry proves to be some kind of economic activity and lottery market possesses its own operation laws, government should conduct proper supervisions and guarantee macro management and moderate control to avoid overdue interventions on lottery market from governments as much as possible[6].

\section{To establish State Lottery Monopoly Administration.}

The priority of lottery legislation is to break government's monopoly in lottery sales and separate department interests. It is the central government who is accessible to lottery sales permission and the enterprises obtaining sales permissions who occupy lottery market. In order to develop lottery, 
government functions should be transformed. Government is responsible to formulate development principles while enterprises are in charge of issuing, which proves to be the development tendency of world lottery industry in the $21^{\text {st }}$ century. Concretely speaking, as the state management organization of lottery industry, lottery monopoly administration should be established. Then current department lotteries (welfare and sports) can be turned into state lotteries, department leaders (Ministry of Finance) into leaders from State Council and current market competition into state monopoly, by which utilization purpose of lottery capital can be better ascertained[7].

\section{To establish and improve lottery legal system.}

Since healthy development of lottery industry bears close connections with mature legal system, the whole lottery industry can be regulated by legislation. Legislations for national lottery should be considered from all aspects, including administrative organizations, issuing subject and purpose and usage to issue lotteries. Besides detailed regulations should be made in the issuing procedures, issuing methods, drawing methods, drawing procedures, calculation method of prize money, funds distribution and usage and disclosure of lottery information. More importantly relations between lottery and other laws and regulations should be coordinated properly. Since currently prominent conflicts in lottery industry exist between issuing party and lottery buyers, lottery legislation should regulate the right and obligation relations between issuing party and buyers and means to seek assistance after conflicts emerge as specifically as each party's burden of proof should be presented.

\section{Countermeasures to Develop Sports Lottery}

According to the current issuing situations of China's sports lottery and international development tendency, in order for a benign development of sports lottery industry, following countermeasures are proposed:

To establish and improve information disclosure system.

It is transparence, justice and fairness that lottery industry lives on. In order to attain people's trust and cement the transparence of lottery market, all lottery organizations should set up and improve information disclosure system which covers the whole process, from lottery issuing to public welfare fund utilization, as soon as possible. Lottery issuing institutions at all levels are supposed to release the issuing rules and winning regulations to the whole society before issuing current lottery; in the meantime, lottery drawing and prize receiving processes should be more transparent and falsification and misleading promotion are forbidden; accountant and law offices recognized by People's Bank of China should be chosen to audit the aggregate sales amount, sales revenue distribution and public welfare fund appropriation and utilization and the auditing results should be published in People's Daily and China Sports Daily regularly to enhance supervisions on lottery issuing and public welfare funds utilizing.

To reinforce promotion to increase people's knowledge of lottery.

With lottery market fostered vigorously and excellent social image established, sports lottery can take a sustainable development path. Therefore sports lottery administrative organizations at all levels should grasp all kinds of opportunities, strengthen promotions, explain the characteristics, effects and significance of sports lottery to citizens, help them learn the differences between lottery and gambling and guarantee correct guidance of public opinions during marketing; at current stage, by means of promotions of nationwide body-building plan funded by lottery public welfare funds, good image of sports lottery, namely "from the people and for the people", should be built up to gradually bestow people with correct perceptions of sporting lottery and guide people to take active parts in sports lottery activities in peace.

\section{To reduce issuing costs.}

In order to reduce issuing costs and improve financing efficiency, advanced facilities should be introduced. If all provincial and city lottery centers spare no efforts to reduce operation costs, whether the commission of lottery outlets will decrease turns out to be proprietors' biggest concern. At present in some domestic provinces and cities, the commission rate of outlets has been adjusted to from 4 percents to 6 percents. 


\section{References}

[1] Cai Youzhi. Analysis of and Research in China's Sports Lottery Market at Current Stage [J]. Journal of Beijing Sports University. 2001.2.166-168.

[2] Ministry of Finance. Financial Management Provision of Lottery Issuing and Sale Organizations [S]. Provision Five 2001.12.9

[3] Ministry of Finance. Financial Management Provision of Lottery Issuing and Sale Organizations [S]. Provision Six 2001.12.9

[4] Xie Qionghuan. Some Questions about Issuing Sports Lottery [J]. Sports Sciences 2000.3.7-9

[5] Jiang Rulin. Reviews on Issuing History of China's Sports Lotteries and Research in Development Tendency in New Century [J]. Journal of Chengdu Sports University. 2001.4.14-17

[6] Wang Jiahong. Legal Views on Sports Lottery Popularity [J]. Sports and Sciences. 2000.1.18-20

[7] Li Zhi. Analysis of and Research in Current Situations of Beijing Computer Sports Lottery Buyers [J]. Journal of Beijing Sports University. 2002.2.163-164. 